\title{
Regionalizing time of concentration using landscape structural patterns of catchments
}

\author{
Bahman Jabbarian Amiri ${ }^{1,2^{*}}$, Junfeng $\mathrm{Gao}^{2}$, Nicola Fohrer ${ }^{3}$, Jan Adamowski ${ }^{4}$ \\ ${ }^{1}$ Department of Environmental Science, Faculty of Natural Resources, University of Tehran, Chamran Blvd., Karaj, Iran. \\ ${ }^{2}$ Key Laboratory of Watershed Geographic Sciences, Nanjing Institute of Geography and Limnology, Chinese Academy of Sciences, \\ 73 East Beijing Road, Nanjing 210008, China. E-mail: GaoJunf@niglas.ac.cn \\ ${ }^{3}$ Department of Hydrology and Water Resources, Institute for Nature Conservation and Resource Management, Christian Albrecht \\ Universitaet zu Kiel, Olshausenstr. 75, 24098 Kiel, Germany. E-mail: nfohrer@hydrology.uni-kiel.de \\ ${ }^{4}$ Department of Bioresource Engineering, Faculty of Agricultural and Environmental Sciences, McGill University, Ste-Anne-de-Bellevue, \\ Québec H9X 3V9, Canada. E-mail: jan.adamowski@mcgill.ca \\ ${ }^{*}$ Corresponding author. E-mail: Jabbarian@ut.ac.ir
}

\begin{abstract}
There is an emerging challenge within water resources on how, and to what extent, borrowing concepts from landscape ecology might help re-define traditional concepts in hydrology in a more tangible manner.

A stepwise regression model was adopted in this study to assess whether the time of concentration of catchments could be explained by five landscape structure-representing metrics for land use/land cover, soil and geological patches, using spatial data from 39 catchments.

The models suggested that the times of concentration of the catchments could be predicted using the measures of four landscape structure-representing metrics, which include contiguity index $\left(r^{2}=0.46, p \leq 0.05\right)$, fractal dimension index $\left(r^{2}=0.51, p \leq 0.05\right)$, related circumscribing circle $\left(r^{2}=0.52, p \leq 0.05\right)$, and shape index $\left(r^{2}=0.47, p \leq 0.05\right)$.

The models indicated that the regularity or irregularity in land use/land cover patch shape played a key role in affecting catchment hydrological response. Our findings revealed that regularity and irregularity in the shape of a given patch (e.g., urban and semi-urban, rangeland and agricultural patches) can affect patch functions in retarding and/or increasing flow accumulation at the catchment scale, which can, in turn, decrease or increase the times of concentration in the catchments.
\end{abstract}

Keywords: Landscape metrics; Time of concentration; Hydrologic Soil Group; Hydrologic response.

\section{INTRODUCTION}

Use of geometrical and mathematical concepts in landscape ecology (e.g., Baker and Cai, 1992; Gustafson, 1998; He et al., 2000; Jaeger, 2000; McGarigal and Marks, 1995; McGarigal et al., 2002; O’Neill et al., 1988; Turner, 1990; Turner and Gardner, 1991) has led to an interesting debate within water resources engineering, planning and management regarding the possibility of explaining hydrological processes in catchments using the metrics of landscape structural patterns. Referring to a well-documented relationship between the pattern and process of surface hydrology (e.g., Van Nieuwenhuyse et al., 2011), it has been hypothesized that hydrological event and response relationships (e.g., Almeida et al., 2014; Fang et al., 2008; Salimi et al., 2016) can be explained explicitly by the landscape attributes of a given catchment. Extending this event-response hypothesis to one of the most significant hydrological responseindicators, time of concentration, using the landscape patterns of a catchment, is a critical area of study.

Response of a catchment to a rainfall event is measured by time of concentration, meaning how quickly or slowly a catchment responds to rainfall input in terms of the time needed for water to flow from the most hydrologically remote point in the catchment to the outlet (USDA, 1986).

There have been extensive applications of time of concentration to hydrological modeling and river engineering works (Fang et al., 2008; Grimaldi et al., 2012; Soulis et al., 2015), but little work has been done in an environmental management context. Knowing a given catchment's behavior in terms of time of concentration can help to prevent and/or minimize the impacts of natural disasters and point source pollution of water resources (Almeida et al., 2014). The suitability of land use allocation at varying scales (from sub-catchment and catchment to basin) can be evaluated for likely hydrological impacts such as the peak discharge, which could be generated due to change in the curve number, an empirical indicator applied in hydrology for estimating direct runoff or infiltration from rainfall excess (USDA, 1986), and consequently that of the time of concentration (Yeo et al., 2007). In this way, catchments of interest could, for example, be developed to increase their resiliency to flooding in a more cost effective manner than allocating significant funds for river engineering projects.

Of the three major landscape features, which are composition, function and structure (Amiri, 2014; Forman and Godron, 1986), the influence of landscape structure on water quantity (Amiri et al., 2016; Lin et al., 2007) and water quality (Amiri and Nakane, 2009; Lee et al., 2009; Paul et al., 2002; Turner and Rabalais, 2003; Uriarte et al., 2011; Uuemma et al., 2007; Wickham et al., 2007) have been studied in catchments.

The study of landscape structure is mainly based on how and to what extent a given function of landscape can be derived from spatial relationships between different shapes of land use and land cover patches within a catchment. Accordingly, there is increasing demand for the development of appropriate indicators, methods and tools to assess how landscape attributes (including composition, structure, and configuration) might affect the functions of a given landscape in hydrological context (Griffith, 2002; Kearns et al., 2005; Rhode et al., 2004).

Landscape-related metrics can also provide reliable information and practical guidelines to develop more environmental- 
ly sound approaches to improve the quantity and quality of water resources (Amiri and Nakane, 2009; del Tánago et al., 2016; Lin et al., 2007; Uuemma et al., 2007; Zhou et al., 2014).

The application of percentage-based measures of catchment attributes have dominated regional studies that examined the relationship between time of concentration and catchment geometric attributes (see: McCuen et al., 1984). To the best of our knowledge, there has been no research on hydrological response in general, and time of concentration in particular, from the standpoint of how and to what extent this time-related indicator can explicitly be explained by the structural patterns of catchments.

The objectives of the present study were therefore to: (i) examine whether total variation in time of concentration can be explained by changes in the metrics which represent structural attributes of the landscape; (ii) evaluate to what extent the total variation in time of concentration can be affected by the hydrologic soil groups (HSGs), and geological permeability classes (GPCs) and (iii) develop models which relate changes in the times of concentration to changes in the metrics of the landscape, pedoscape, and lithoscape structures.

\section{MATERIALS AND METHODS Study area}

The study area in the southern basin of the Caspian Sea in Iran was selected due to its diversified land use/land cover, soil types and geological formations (Figure 1; Table 1). The basin area covers $38,467 \mathrm{~km}^{2}\left(49^{\circ} 48^{\prime}\right.$ to $54^{\circ} 41^{\prime} \mathrm{N}$ lon., $35^{\circ} 36^{\prime}$ to $37^{\circ} 19^{\prime}$ E. lat.) across a wide range of elevations ( $-16 \mathrm{~m}$ to $4782 \mathrm{~m}$ a.s.1.). While 59 rivers drain precipitation from within the basin to the Caspian Sea, limitations in data access and the need to achieve a homogeneous data set led to only 39 catchments being investigated in the present study. These catchments vary in area (32 to $\left.2325 \mathrm{~km}^{2}\right)$ and in 40-year (1971-2010) mean discharge $\left(0.47\right.$ to $\left.21 \mathrm{~m}^{3} \mathrm{~s}^{-1}\right)$, and are dominated by forest cover $(57.4 \%)$, while rangeland, farmland, urban and semi-urban areas and bodies of water (e.g., wetlands) account for $25.9 \%$, $11.7 \%, 1.6 \%$, and less than $1 \%$ of the total area, respectively.

The underlying bedrock is predominantly made up of granite and andesite. On average, the moderate infilterable soil (S3
Table 1. Distribution statistics of the geometric attributes of the catchments.

\begin{tabular}{lccccc}
\hline & \multicolumn{5}{c}{ Catchment metrics } \\
\cline { 2 - 6 } $\begin{array}{l}\text { Distribution } \\
\text { statistic }\end{array}$ & $\begin{array}{c}\text { Area } \\
\left(\mathrm{km}^{2}\right)\end{array}$ & $\begin{array}{c}\text { Slope } \\
(\%)\end{array}$ & $\begin{array}{c}\text { Main } \\
\text { stream } \\
\text { length } \\
(\mathrm{km})\end{array}$ & $\begin{array}{c}\text { Drainage } \\
\text { density } \\
(\mathrm{km})\end{array}$ & $\begin{array}{c}\text { Conc. } \\
\text { time } \\
(\mathrm{min})\end{array}$ \\
\hline Maximum & 2325.69 & 15.47 & 143.75 & 63.94 & 21.59 \\
Minimum & 32.82 & 0.29 & 5.34 & 0.20 & 427.58 \\
Mean & 554.74 & 7.74 & 43.30 & 8.78 & 97.09 \\
Std. dev & 584.03 & 4.48 & 32.82 & 14.82 & 76.18 \\
Median & 293.00 & 7.68 & 35.16 & 0.26 & 82.53 \\
Kurtosis & 1.48 & -1.05 & 1.65 & 5.09 & 8.44 \\
Skewness & 1.47 & 0.13 & 1.29 & 2.27 & 2.41 \\
\hline
\end{tabular}

group) and the high infilterable soil (S1) (USDA, 1986) cover $53.9 \%$ and $4.1 \%$ of the catchments, respectively.

\section{Data sets}

Digital elevation models $(30 \mathrm{~m} \times 30 \mathrm{~m})$ downloaded from the United States Geological Survey (USGS) served to delineate upstream catchment boundaries. A digital land use/land cover (LULC) map (2002; scale 1:250,000) was obtained from the Forest, Range, and Watershed Management Organization of Iran (http://frw.org.ir). Land suitability and geological maps (scale 1:250,000) were obtained from the Iranian Soil and Water Research Institute (http://www.swri.ir) and the Geological Survey of Iran (http://www.gsi.ir), respectively.

\section{Methods}

The main steps of the present study are depicted in Figure 2. All the information layers were first transformed into a common digital format, then co-registered with the WGS84 source (zone 39n). The upper catchment boundaries were then delineated by applying the digital elevation model for each of the river gauging stations, applying Digital elevation models (30-m resolution), which were downloaded from the United States Geological Survey (USGS) by Arc Hydro tools in the ArcGIS environment.

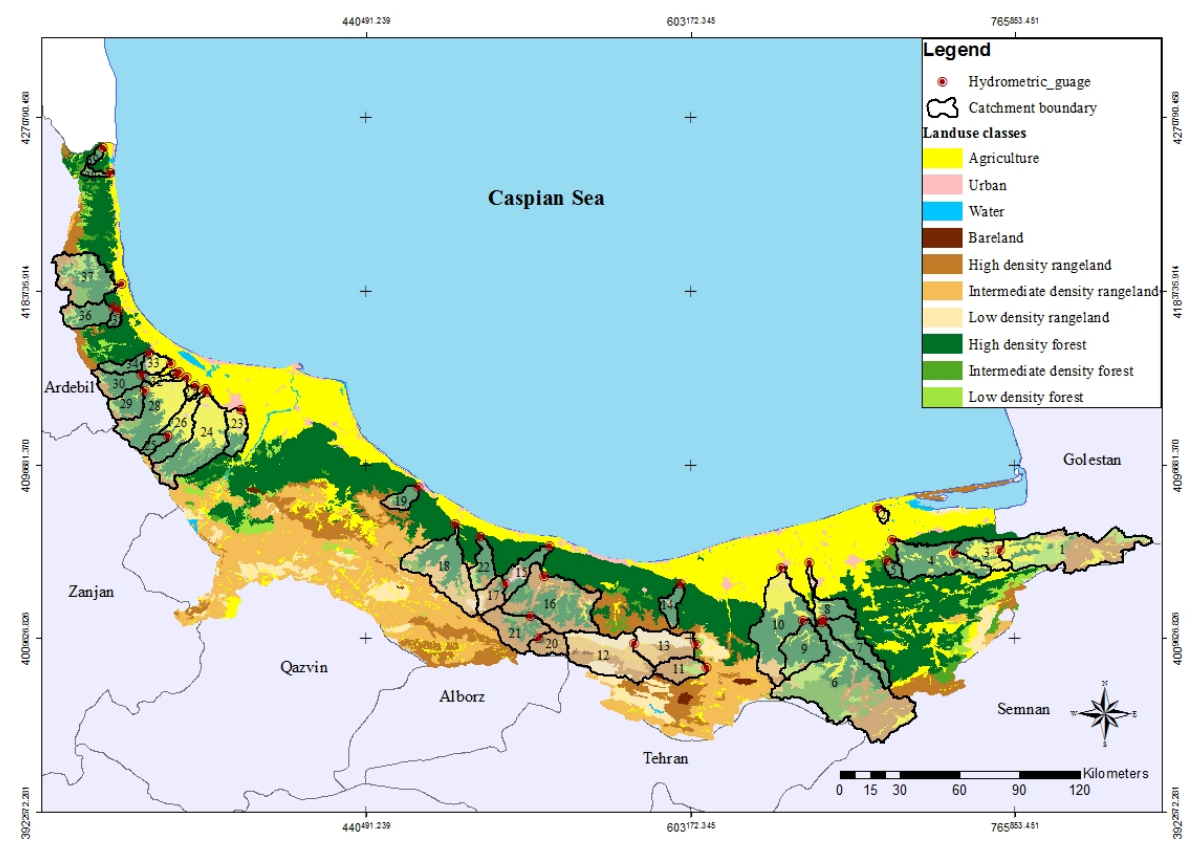

Fig. 1. Geographical location of the catchments in the southern basin of the Caspian Sea. 


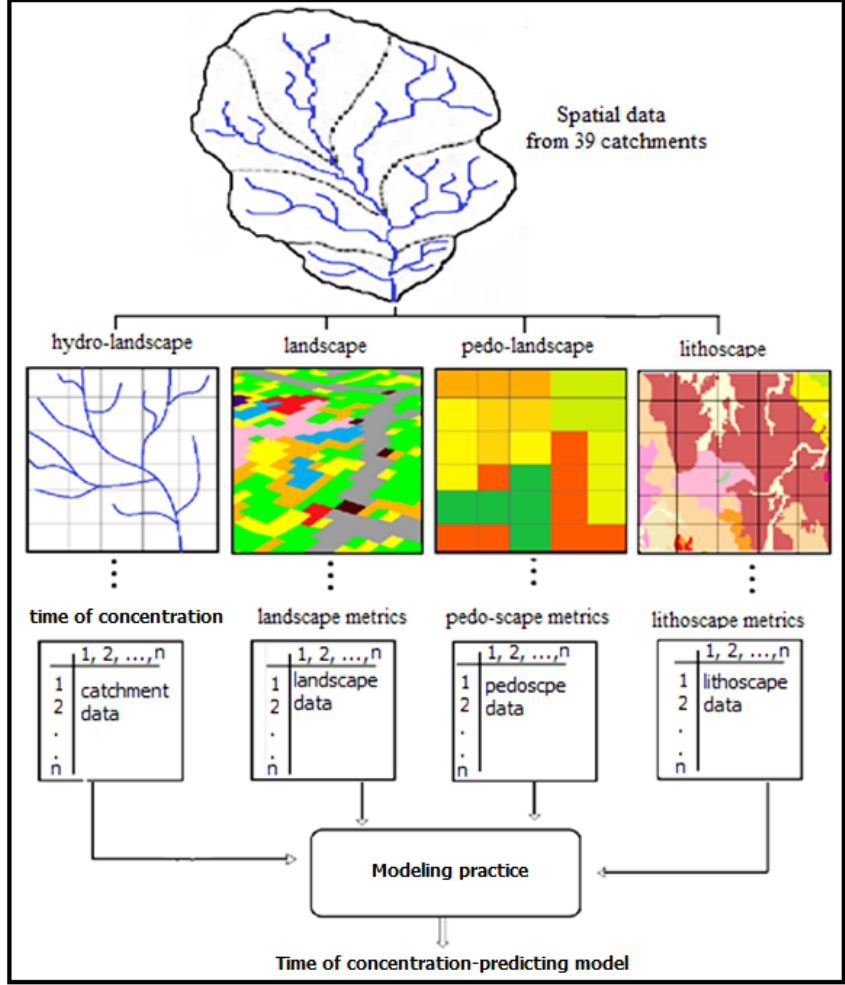

Fig. 2. Main steps of the study.

The study was based on finding a sufficient number of homogeneous catchments in the study area. The main criteria for finding a homogeneous catchment was to select those catchments whose areas vary within three standard deviations of the mean catchment area in our study area.

The LULC map (http://frw.org.ir, 2002) was aggregated into eight classes, including:

- $\quad$ forest (high density, intermediate density, low density; F1, F2, F3, respectively),

- rangeland (high density, intermediate density, low density; R1, R2, R3, respectively),

- urban and semi-urban (U) and,

- $\quad$ agricultural lands (A).

Reclassification of the land suitability map (http://www.swri.ir) was conducted to generate a map of hydrologic soil groups (HSGs) with four soil groups, where their infiltration rates decrease, respectively (USDA, 1986). Accordingly, Group S1 includes sand, loamy sand or sandy loam types of soils, where low runoff potential and high infiltration are their main characteristics (even when thoroughly wetted). Group $\mathbf{S 2}$ is composed of silt loam or loam, where this HSG has a moderate infiltration rate when thoroughly wetted. Group S3 is formed by sandy clay loam, which has low infiltration rates when thoroughly wetted. Group S4 soils are clay loam, silty clay loam, sandy clay, silty clay or clay. This HSG has the highest runoff potential and the lowest infiltration (Sangani et al., 2015; USDA, 1986) (Figure 3).

Digital geological maps (http:/www.gsi.ir, scale $1: 250,000$ ), documenting 19 geological classes (Sangani et al., 2015), were reclassified into three geological permeability classes (GPCs) based on effective porosity, type, size and connectivity of cavities, rock density, pressure gradient and features of the fluid such as viscosity (Fatehi et al., 2015). Spatial variations in geological permeability across the study area was re-classified based on the standpoint of the measure of the rock permeability, which was accordingly termed low permeable rocks G1, medium permeable rocks G2 and high permeable rocks G3.

The LULC and HSGs maps were then overlaid on a catchment boundary map, in order to calculate the true extent (\%) of each ecological attribute (LULC, HSGs, and GPCs) within the catchments. Thereafter, the landscape structural metrics of the shape index $(s h p)$, fractal dimension index (frac), perimeterarea ratio (para), related circumscribing circle (cir), and contiguity index (con) were calculated at the class level for each of the catchment's ecological attributes (Tables 2 and 3). These landscape metrics were calculated using:

$$
\begin{aligned}
& \text { shapeindex }=\frac{P_{i j}}{\min P_{i j}} \\
& \text { fractal dimensionindex }=\frac{2 \ln \left(0.25 P_{i j}\right)}{\ln a_{i j}} \\
& \text { perimeter - area ratio }=\frac{P_{i j}}{a_{i j}} \\
& \text { related circumscribing circle }=1-\left[\frac{a_{i j}}{a_{i j}^{s}}\right] \\
& \text { contiguityindex }=\frac{\left[\frac{\sum_{r=1}^{z} C_{i j r}}{a_{i j}}\right]-1}{v-1}
\end{aligned}
$$

where

$P_{i j}$ perimeter $(\mathrm{m})$ of patch $i j$,

$a_{i j}$ area $\left(\mathrm{m}^{2}\right)$ of patch $i j$,

$a_{i j}^{s}$ area $\left(\mathrm{m}^{2}\right)$ of smallest circumscribing circle around patch $i j$,

$C_{i j r}$ contiguity value for pixel $\boldsymbol{r}$ in patch $i j$,

$v$ Sum of the values in a 3-by-3 cell template.

This approach in calculating the landscape structurerepresenting metrics resulted in 15 potentially relevant landscape metrics for a given catchment. For example, in the case of the shape index (shp), the following landscape metrics were calculated:

- $\quad \mathrm{F} 1_{s h p}, \mathrm{~F} 2_{s h p}, \mathrm{~F} 3_{\text {shp }}, \mathrm{R} 1_{s h p}, \mathrm{R} 2_{s h p}, \mathrm{R} 3_{s h p}, \mathrm{U}_{s h p}, \mathrm{~A}_{s h p}$ (from LULC), namely the shape index for within-catchment patches of high, medium and low density forest; high, medium and low density rangeland; urban and semi-urban and agricultural patches, respectively.

- $\quad \mathrm{S} 1_{s h p}, \mathrm{~S} 2_{s h p}, \mathrm{~S} 3_{s h p}, \mathrm{~S} 4_{s h p}$ (from HSGs), namely the shape index for within-catchment patches of soil, with infiltration rates varying from very high to low, respectively.

$\mathrm{G} 1_{\text {shp }}, \mathrm{G} 2_{\text {shp }}, \mathrm{G} 3_{\text {shp }}$, (from GPCs), namely the shape index for within-catchment patches of low, medium and high geological permeability, respectively.

FRAGSTATS (McGarigal et al., 2012) was used to calculate landscape metrics of catchment LULCS, HSGs, and GPCs as ecological attributes of the catchments.

Although there are a number of formulae for estimation of time of concentration, each of those formulae can be applied considering their limitations including, but not limited, to catchment area. Accordingly, considering that the catchments' areas vary between 33 to $2325 \mathrm{~km}^{2}$, the formula of Johnson-Cross (1949) was adopted to calculate the time of concentration as an indicator of hydrological response, using the following formula (Li and Chibber, 2008; Salimi et al., 2017): 


$$
T_{c}=300 L^{0.5} \cdot S^{-0.5}
$$

where

$T_{c}$ is the time of concentration ( $\mathrm{min}$ ),

$L$ is catchment length (mi),

$S$ is the catchment slope $(\mathrm{ft} / \mathrm{mi})$.

To model the relationship between landscape metrics of a given catchment's ecological attributes and time of concentration, a stepwise regression analysis (entry criterion $p \leq 0.05$, exclusion criterion $p \geq 0.100$ ) was applied to develop multiple linear regression models through which the times of concentration (dependent variable; min) could be explained by an individual pairing of landscape metric (cir, con, frac, para, and $s h p)$ and LULCs, HSGs or GPCs (e.g., $T_{c}=f\left(\mathrm{~F}_{\text {shp }}\right)$ independent variables). This yielded the equation:

$$
y_{i}=\beta_{0}+\beta_{1} x_{1}+\beta_{2} x_{2}+\ldots+\beta_{n-1} x_{n-1}+\varepsilon_{i}
$$

where

$y_{i}$ is the time of concentration ( $\mathrm{min}$ ) of the catchment, $x_{1} \ldots x_{n-1}$ are the catchment landscape metrics (cir, con, frac, para, and $s h p$ ),

$\beta_{1} \ldots \beta_{n-1}$ are the coefficients of the catchment landscape metrics retained, with $p \leq 0.05$,

$\beta_{0}$ is a constant, with $p \leq 0.05$, and

$\varepsilon_{i}$ is the error for the time of concentration.

Inter-variable collinearity of the developed models was assessed using the variation inflation factor (VIF), where a VIF < 10 for all model parameters indicated a lack of collinearity (Chatterjee et al., 2000; Neter et al., 1996). The models' goodness of fit was evaluated using scatter plots of observed $v s$. predicted values (Figure 4) (Ahearn et. al., 2005). The last critical criteria for choosing the candidate model was to clarify to what extent a given candidate model was useful from the perspective of landscape ecology. All statistical analyses were conducted by IBM SPSS for Windows, Release 19.

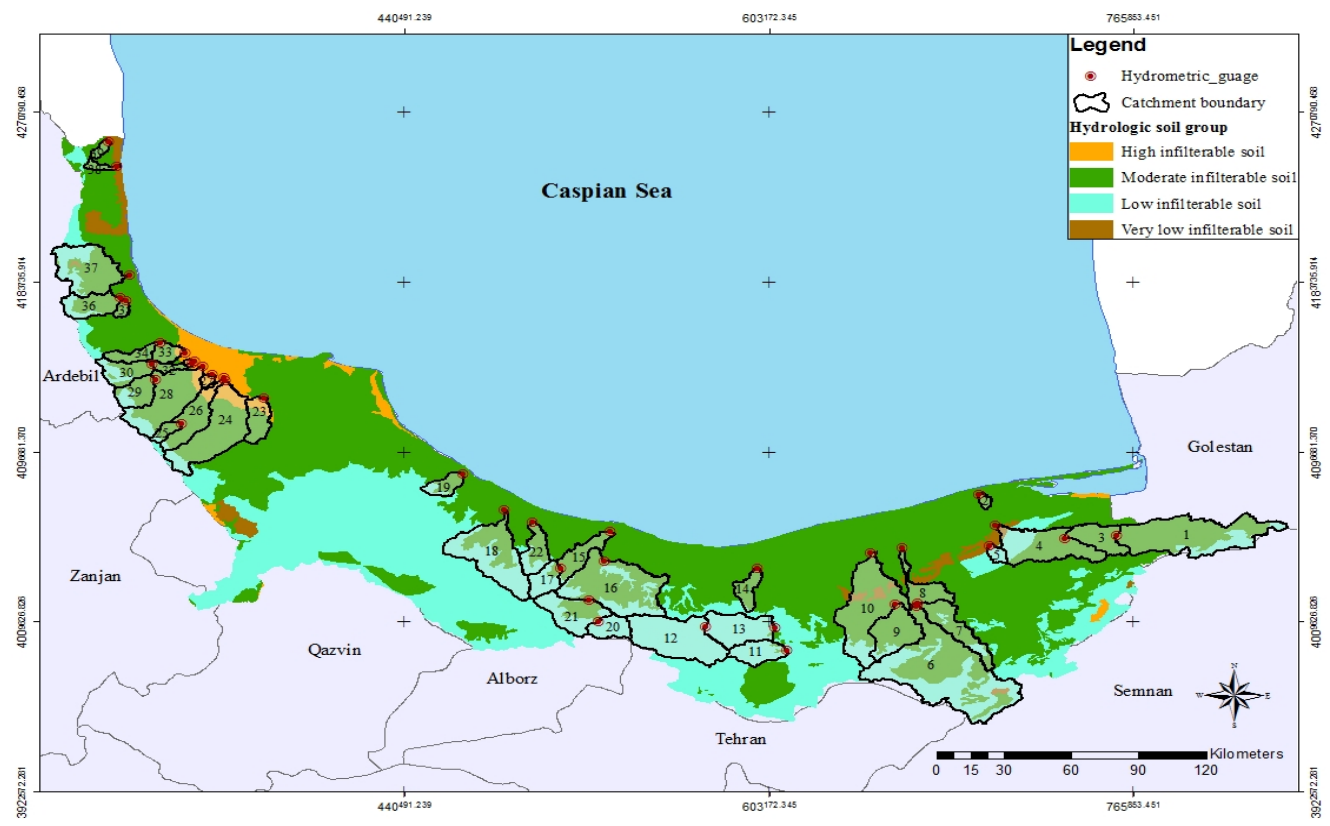

Fig. 3. Spatial distribution of hydrologic soil groups in the southern basin of the Caspian Sea.

\begin{tabular}{|c|c|c|c|c|c|c|c|c|c|}
\hline \multirow{3}{*}{$\begin{array}{l}\stackrel{0}{E} \\
\sum_{\Sigma}^{0}\end{array}$} & \multirow{3}{*}{ 总 } & \multicolumn{8}{|c|}{ Land use/cover classes } \\
\hline & & \multicolumn{3}{|c|}{ Rangeland } & \multirow[b]{2}{*}{$\begin{array}{l}\text { Farmland } \\
\text { (A) }\end{array}$} & \multicolumn{3}{|c|}{ Forest } & \multirow{2}{*}{$\begin{array}{l}\text { Urban and } \\
\text { semi-urban } \\
\text { (U) }\end{array}$} \\
\hline & & R1 & $\mathrm{R} 2$ & R3 & & F1 & F2 & F3 & \\
\hline \multirow{4}{*}{ 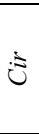 } & Max. & 0.85 & 0.83 & 0.73 & 0.93 & 0.79 & 0.88 & 0.91 & 0.94 \\
\hline & Min. & 0.00 & 0.00 & 0.00 & 0.00 & 0.00 & 0.00 & 0.00 & 0.00 \\
\hline & Median & 0.65 & 0.00 & 0.00 & 0.69 & 0.60 & 0.64 & 0.51 & 0.61 \\
\hline & Mean & $0.57 \pm 0.29$ & $0.29 \pm 0.35$ & $0.12 \pm 0.26$ & $0.60 \pm 0.27$ & $0.53 \pm 0.23$ & $0.51 \pm 0.32$ & $0.43 \pm 0.33$ & $0.44 \pm 0.32$ \\
\hline \multirow{3}{*}{ ฮี } & Max. & 0.99 & 0.98 & 0.99 & 0.99 & 1.00 & 0.98 & 0.99 & 0.97 \\
\hline & Median & 0.95 & 0.00 & 0.00 & 0.87 & 0.66 & 0.73 & 0.62 & 0.81 \\
\hline & Mean & $0.71 \pm 0.38$ & $0.32 \pm 0.43$ & $0.15 \pm 0.34$ & $0.70 \pm 0.32$ & $0.65 \pm 0.32$ & $0.62 \pm 0.39$ & $0.52 \pm 0.40$ & $0.56 \pm 0.41$ \\
\hline \multirow{4}{*}{ 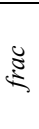 } & Max. & 1.15 & 1.15 & 1.09 & 1.19 & 1.18 & 1.27 & 1.17 & 1.18 \\
\hline & Min. & 0.00 & 0.00 & 0.00 & 0.00 & 0.00 & 0.00 & 0.00 & 0.00 \\
\hline & Median & 1.11 & 0.00 & 0.00 & 1.10 & 1.09 & 1.10 & 1.10 & 1.07 \\
\hline & Mean & $0.91 \pm 0.43$ & $0.45 \pm 0.55$ & $0.19 \pm 0.42$ & $0.97 \pm 0.38$ & $0.96 \pm 0.37$ & $0.83 \pm 0.50$ & $0.74 \pm 0.53$ & $0.73 \pm 0.52$ \\
\hline \multirow{3}{*}{ 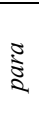 } & Max. & 907.81 & 908.64 & 528.61 & 825.15 & 772.88 & 832.33 & 691.27 & 700.84 \\
\hline & Min. & 0.00 & 0.00 & 0.00 & 0.00 & 0.00 & 0.00 & 0.00 & 0.00 \\
\hline & Mean & $129.10 \pm 230.48$ & $110.88 \pm 255.43$ & $32.01 \pm 117.86$ & $211.87 \pm 227.59$ & $272.65 \pm 265.01$ & $151.80 \pm 201.09$ & $181.42 \pm 230.25$ & $124.49 \pm 151.50$ \\
\hline \multirow{4}{*}{$\frac{5}{5}$} & Max. & 4.04 & 3.67 & 2.23 & 4.63 & 5.97 & 10.83 & 3.64 & 3.61 \\
\hline & Min. & 0.00 & 0.00 & 0.00 & 0.00 & 0.00 & 0.00 & 0.00 & 0.00 \\
\hline & Median & 2.49 & 0.00 & 0.00 & 2.11 & 2.23 & 2.15 & 2.11 & 1.56 \\
\hline & Mean & $2.12 \pm 1.17$ & $0.88 \pm 1.12$ & $0.33 \pm 0.72$ & $2.21 \pm 1.24$ & $2.26 \pm 1.33$ & $2.11 \pm 1.97$ & $1.73 \pm 1.33$ & $1.28 \pm 1.02$ \\
\hline
\end{tabular}

Table 2. Catchment metric distribution statistics for land use/land cover classes at the patch level. 
Regionalizing time of concentration using landscape structural patterns of catchments

Table 3. Catchment metric distribution statistics by hydrologic soil groups and geological permeability group at the patch level across.

\begin{tabular}{|c|c|c|c|c|c|c|c|c|}
\hline \multirow{2}{*}{ 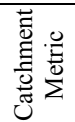 } & \multirow{2}{*}{ 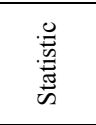 } & \multicolumn{4}{|c|}{ Hydrologic soil group } & \multicolumn{3}{|c|}{ Geological permeability class } \\
\hline & & $\mathrm{S} 1$ & S2 & $\mathrm{S} 3$ & S4 & G1 & G2 & G3 \\
\hline \multirow{4}{*}{ ثे } & Max. & 0.84 & 0.83 & 0.84 & 0.76 & 0.76 & 0.81 & 0.82 \\
\hline & Min. & 0.00 & 0.00 & 0.00 & 0.00 & 0.44 & 0.00 & 0.00 \\
\hline & Median & 0.28 & 0.55 & 0.45 & 0.47 & 0.66 & 0.67 & 0.66 \\
\hline & Mean & $0.29 \pm 0.31$ & $0.45 \pm 0.30$ & $0.38 \pm 0.33$ & $0.34 \pm 0.31$ & $0.64 \pm 0.08$ & $0.60 \pm 0.20$ & $0.49 \pm 0.34$ \\
\hline \multirow{4}{*}{$\tilde{\delta}$} & Max. & 1.00 & 1.00 & 1.00 & 1.00 & 1.00 & 0.99 & 1.00 \\
\hline & Min. & 0.00 & 0.00 & 0.00 & 0.00 & 0.19 & 0.00 & 0.00 \\
\hline & Median & 0.87 & 0.97 & 0.71 & 0.94 & 0.93 & 0.95 & 0.93 \\
\hline & Mean & $0.50 \pm 0.50$ & $0.67 \pm 0.44$ & $0.54 \pm 0.47$ & $0.55 \pm 0.49$ & $0.88 \pm 0.14$ & $0.83 \pm 0.27$ & $0.65 \pm 0.44$ \\
\hline \multirow{4}{*}{$\mathbb{E}$} & Max. & 1.13 & 1.13 & 1.12 & 1.12 & 1.10 & 1.12 & 1.12 \\
\hline & Min. & 0.00 & 0.00 & 0.00 & 0.00 & 1.04 & 0.00 & 0.00 \\
\hline & Median & 1.03 & 1.06 & 1.05 & 1.05 & 1.07 & 1.07 & 1.07 \\
\hline & Mean & $0.54 \pm 0.54$ & $0.77 \pm 0.49$ & $0.63 \pm 0.54$ & $0.60 \pm 0.54$ & $1.07 \pm 0.02$ & $0.99 \pm 0.29$ & $0.75 \pm 0.50$ \\
\hline \multirow{3}{*}{$\frac{1}{5}$} & Max. & 143.59 & 665.52 & 466.91 & 280.31 & 1046.17 & 538.06 & 183.18 \\
\hline & Min. & 0.00 & 0.00 & 0.00 & 0.00 & 5.73 & 0.00 & 0.00 \\
\hline & Median & 3.76 & 5.85 & 4.16 & 4.58 & 80.23 & 43.56 & 27.09 \\
\hline \multirow{4}{*}{$\frac{5}{5}$} & Max. & 3.26 & 2.65 & 2.93 & 3.20 & 2.75 & 2.68 & 2.56 \\
\hline & Min. & 0.00 & 0.00 & 0.00 & 0.00 & 1.30 & 0.00 & 0.00 \\
\hline & Median & 1.36 & 1.67 & 1.53 & 1.46 & 1.77 & 1.88 & 1.66 \\
\hline & Mean & $0.87 \pm 0.90$ & $1.32 \pm 0.90$ & $1.10 \pm 0.97$ & $1.05 \pm 0.99$ & $1.82 \pm 0.29$ & $1.82 \pm 0.60$ & $1.28 \pm 0.90$ \\
\hline
\end{tabular}

\section{RESULTS AND DISCUSSION}

Stepwise regression models were developed for the time of concentration using the five landscape structure-related metrics (con, frac, para, cir, shp) for land use land cover, soil and geology (Equations (8) to (12)). Table 4 shows other statistics of these models. The total variation in times of concentration were explained by the landscape structural metrics of catchments in the following multiple linear regression models:

$$
\begin{aligned}
\log y= & 1.587+0.555 U_{c i r}-0.530 S 4_{c i r}+0.469 G 3_{c i r} \\
\log y= & 1.311+0.243 U_{c o n}+0.444 A_{c o n}-0.233 S 3_{c o n} \\
\log y= & -3.963+0.185 U_{\text {frac }}+0.364 A_{\text {frac }}+ \\
& +0.187 R 1_{\text {frac }}+4.925 G 3_{\text {frac }}
\end{aligned}
$$

$\log y=1.806+0.001 G 2_{\text {para }}$

$$
\log y=1.633+0.11 U_{s h p}-0.165 S 4_{s h p}+0.221 G 3_{s h p}
$$

where

$\log y$ is the logarithmic measure of time of concentration of the catchment in base of 10 ,

cir is the mean related circumscribing circle index for a given class of the landscape, pedoscape, and lithoscape of the catchment,

con is the mean contiguity index for a given class of the landscape, pedoscape, and lithoscape of the catchment,

frac is the mean fractal dimension circle index for a given class of the landscape, pedoscape, and lithoscape of the catchment, para is the mean parameter-area ratio index for a given class of the landscape, pedoscape, and lithoscape of the catchment, shp is the mean shape index for a given class of the landscape, pedoscape, and lithoscape of the catchment,

$U$ is the urban and semi-urban class,

$A$ is the agriculture class,

$R 1$ is the high density rangeland class,

$S 3$ is the moderate infilterable soil group,

$S 4$ is the low infilterable soil group,

$G 2$ is the medium permeable geological class, and
$G 3$ is the highly permeable geological class.

The regression models suggested that times of concentration of the catchments could be predicted using four landscape structure-representing metrics out of five: contiguity index $\left(r^{2}=0.46, p \leq 0.05\right)$, fractal dimension index $\left(r^{2}=0.51\right.$, $p \leq 0.05)$, related circumscribing circle $\left(r^{2}=0.52, p \leq 0.05\right)$, and shape index $\left(r^{2}=0.47, p \leq 0.05\right)$ (Table 4).

Eqs. (8) to (12) reveal that only seven LULC classes (out of ten), including urban and semi-urban (U), agriculture (A), high density rangeland (R1), moderate infilterable soil group (S3), low infilterable soil group (S4), medium permeable geological class (G2) and highly permeable geological class (G3), were relevant based on the stepwise regression modeling.

Moreover, although there is no model in which the explanatory variable of low permeable geological class (G1) could partially explain total variation in the time of concentration, the presence of the highly permeable geological class (G3) was observed in all the models except for Eqs. (9) and (11).

To be more specific, Eq. (8) suggests that there is a direct association between the measures of time of concentration and the related circumscribing circle indices of urban and semi urban patches $\left(\mathrm{U}_{\mathrm{cir}}\right)$, and highly permeable geological patches $\left(\mathrm{G} 3_{\mathrm{cir}}\right)$. Accordingly, if the related circumscribing circle indices, hereafter called the circularity index, of the urban and semi-urban patches and that of the highly permeable geological patches increase, the time of concentration for the catchment will increase. The circularity index is a measure for assessing the extent to which the shape of a given patch or class deviates from a convoluted shape and approaches a narrow and elongated one (Turner et al., 2001). It varies from 0 for the convoluted patches to 1 for the elongated ones (Rutledge, 2003).

The model revealed that urban and semi-urban patches, with relatively narrow and elongated shapes, would contribute more to the runoff generation process than urban and semi-urban patches with a relatively convoluted shape in the catchments under study. In contrast, if the circularity index of the low infilterable soil patches $\left(\mathrm{S}_{\text {cir }}\right)$ increases, the time of concentration will decrease for the catchments. It implies that elongating the shape of the low infilterable soil patches due to an increase in the circularity index would contribute to generating an overflow process in a given catchment, rather than a convolution in the shape of the low infilterable soil patches. 


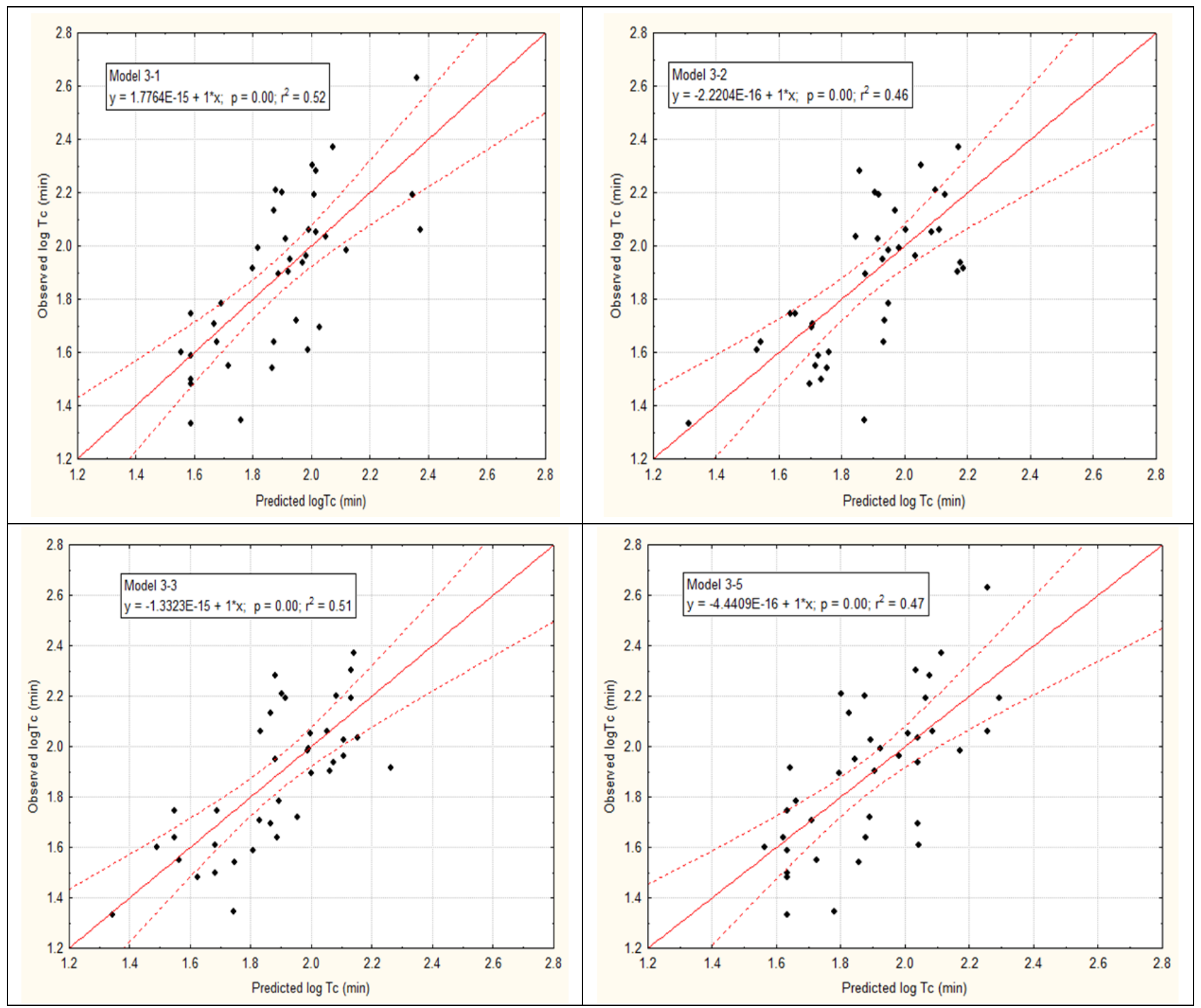

Fig. 4. Predicted vs. observed values for the times of concentration in the study catchments.

Table 4 and Eq. (9) show that $46 \%$ of the total variation in times of concentration of the catchments can be explained by the mean measure of the contiguity index of the urban and semi-urban and agricultural patches ( $A_{c o n}$ and $U_{c o n}$, respectively), and highly permeable geological patches $\left(G 3_{c o n}\right)$ called (termed lithoscape metric). Moreover, it suggests that the mean measure of the contiguity indices of the urban and semi-urban and agricultural patches, and that of the highly permeable geological patches, are positively related to the times of concentration of the catchments.

This index indicates to what extent a set of patches are spatially connected and how far homogenous and heterogeneous patches are in relation to each other, respectively. It varies between $0 \leq$ contiguityindex $\leq 1$ (Rutledge, 2003), and increasing the measure of the index indicates that the patches of interest are larger, more continuous and less dispersed for homogenous patches or less interspersed for heterogeneous patches. A higher contiguity index signifies that more spatially connected and extensive patches can be expected in a given landscape and vice versa (Turner et al., 2001).

As a consequence, Eq. (9) suggests if the contiguity indices for the urban and semi-urban class, and agricultural and highly permeable geological patches increase in a given catchment, the time of concentration of the catchment will increase. If the distances for those patches are decreased, instead of contributing to the overflow process, those patches might contribute to the infiltration process within the catchment.

The mean measure of fractal dimension indices of the urban and semi-urban class, and agricultural and high density rangeland patches $\left(\mathrm{U}_{\text {frac }}, \mathrm{A}_{\text {frac }}\right.$ and $\mathrm{R} 1_{\text {frac }}$, respectively), and highly permeable geological patches $\left(\mathrm{G} 3_{\text {frac }}\right)$ as a lithoscape metric, explains $51 \%$ of the total variation in the time of concentration of the catchments (Table 4; Eq. (10)).

The fractal dimension metric varies $(1 \leq$ fractal dimension index $\leq 2$ ), and measures the shape complexity of a patch or a set of patches (of a given class) (Rutledge, 2003; Turner et al., 2001). If the metric approaches one, the patch is regular (square) in shape; approaching its upper limit results in a more irregular (convoluted) patch (Rutledge, 2003).

Eq. (10) indicates that the more irregular the shape of the urban and semi-urban patches, and the agricultural and intermediate density rangeland patches, the higher the time of concentration. This function might be due to a retarding role of the convoluted patch shapes in draining water from their surfaces into the drainage networks of the catchments.

Although there is well-documented evidence on the impacts of urban, semi-urban and agricultural areas in contributing to runoff processes at different scales (e.g., Deelstra et al., 2014; 
Regionalizing time of concentration using landscape structural patterns of catchments

Table 4. Statistics of regression models for the times of concentration in the study catchments based on different landscape structural metrics.

\begin{tabular}{|c|c|c|c|c|c|c|c|c|c|}
\hline \multicolumn{2}{|c|}{ Model } & \multicolumn{3}{|c|}{ Coefficients } & \multirow{2}{*}{$r^{2}$} & \multirow{2}{*}{$T_{c}(\min )$} & \multirow{2}{*}{ Sig. } & \multicolumn{2}{|c|}{ Collinearity statistics } \\
\hline No. & Variable & $\mathrm{B}$ & Std. error & Beta & & & & Tolerance & VIF \\
\hline \multirow{4}{*}{ Eq. (8) } & Cons. & 1.587 & 0.071 & & \multirow{4}{*}{0.52} & 22.295 & 0.000 & & \\
\hline & $\mathrm{G} 3_{\text {cir }}$ & 0.469 & 0.116 & 0.509 & & 4.038 & 0.000 & 0.866 & 1.155 \\
\hline & $\mathrm{U}_{\mathrm{cir}}$ & 0.555 & 0.125 & 0.629 & & 4.427 & 0.000 & 0.682 & 1.467 \\
\hline & $\mathrm{S} 4_{\text {cir }}$ & -0.530 & 0.144 & -0.547 & & -3.693 & 0.001 & 0.627 & 1.594 \\
\hline \multirow{4}{*}{ Eq. (9) } & Cons. & 1.311 & 0.116 & & \multirow{4}{*}{0.46} & 11.260 & 0.000 & & \\
\hline & $\mathrm{U}_{\text {con }}$ & 0.243 & 0.098 & 0.337 & & 2.470 & 0.019 & 0.835 & 1.198 \\
\hline & $\mathrm{A}_{\text {con }}$ & 0.444 & 0.121 & 0.472 & & 3.667 & 0.001 & 0.938 & 1.067 \\
\hline & $\mathrm{S} 3_{\text {con }}$ & 0.233 & 0.090 & 0.364 & & 2.589 & 0.014 & 0.789 & 1.268 \\
\hline \multirow{5}{*}{ Eq. (10) } & Cons. & -3.963 & 2.501 & & \multirow{5}{*}{0.51} & -1.584 & 0.122 & & \\
\hline & $\mathrm{U}_{\text {frac }}$ & 0.185 & 0.072 & 0.323 & & 2.570 & 0.015 & 0.915 & 1.093 \\
\hline & $A_{\text {frac }}$ & 0.364 & 0.096 & 0.460 & & 3.780 & 0.001 & 0.975 & 1.026 \\
\hline & $\mathrm{R} 1_{\text {frac }}$ & 0.178 & 0.066 & 0.326 & & 2.680 & 0.011 & 0.974 & 1.027 \\
\hline & $\mathrm{G} 3_{\text {frac }}$ & 4.925 & 2.342 & 0.264 & & 2.103 & 0.043 & 0.917 & 1.090 \\
\hline \multirow{2}{*}{ Eq. (11) } & Cons. & 1.806 & 0.058 & & \multirow{2}{*}{0.12} & 31.310 & 0.000 & & \\
\hline & $\mathrm{G} 2_{\text {para }}$ & 0.001 & 0.000 & 0.342 & & 2.211 & 0.033 & 1.000 & 1.000 \\
\hline \multirow{4}{*}{ Eq. (12) } & Cons. & 1.633 & 0.071 & & \multirow{4}{*}{0.47} & 22.868 & 0.000 & & \\
\hline & $\mathrm{G} 3_{\mathrm{shp}}$ & 0.221 & 0.053 & 0.667 & & 4.194 & 0.000 & 0.602 & 1.662 \\
\hline & $\mathrm{S} 4_{\text {shp }}$ & -0.165 & 0.048 & -0.547 & & -3.454 & 0.001 & 0.608 & 1.646 \\
\hline & $\mathrm{U}_{\text {shp }}$ & 0.110 & 0.039 & 0.373 & & 2.845 & 0.007 & 0.885 & 1.130 \\
\hline
\end{tabular}

Gallo et al., 2013; Hundecha and Bárdossy, 2004; Niehoff et al., 2002; Olang et al., 2014; Sun et al., 2016; Wijesekara et al., 2012), the findings of the present study suggest that varying the shape of those types of patches from a square shape to a convoluted shape might change their function in the runoff generation process.

Table 4 reveals $47 \%$ of the total variation in the time of concentration of the catchments can be explained by the mean measure of the shape index of the urban and semi-urban patches $\left(U_{s h p}\right)$, and those of the highly permeable geological patches $\left(\mathrm{G} 3_{\text {shp }}\right)$ and the low infilterable soil patches (S4 shp) (Eq. (12)).

The shape index can be considered one of the simplest and most understandable measures to assess the overall complexity of a patch (Turner et al., 2001). It varies from 1 to $\infty$ (Rutledge, 2003). Approaching the low limit implies that the patches of interest are square in shape, while approaching the high limit indicates the patches are of a more irregular shape (Rutledge, 2003). Accordingly, regularity or irregularity in the shape of a given patch, regardless of its prevalent function in a hydrological context, might present a different understanding of patch function in a new arena (termed landscape hydrology). These contradictory functions can be inferred from the role of the shape indices of the urban and semi-urban patches $\left(\mathrm{U}_{s h p}\right)$ and highly permeable geological patches $\left(\mathrm{G} 3_{\text {shp }}\right)$ in Eq. (12).

\section{CONCLUSIONS}

This study demonstrated that landscape structural metrics can explain a significant amount of the variation in time of concentration of catchments. To determine the extent that landscape structural metrics could contribute to predicting the time of concentration, a multiple linear regression approach (due to its inherent features that help explore the hidden dimensions of relationships between the components of the system) was applied to develop the models. Possible relationships were examined using geospatial data from 39 catchments, which are geographically distributed in the southern basin of the Caspian Sea. The coefficients of determination for the multiple regression models varied from 0.12 to 0.52 .

Applying the models is restricted to the specific range of variables for the areas of the particular catchments under study (32 to $2325 \mathrm{~km}^{2}$ ). Below and above this size, local or regional variations might play an important role in explaining the variation in the times of concentration, which varied from 21 to 427 minutes.
The present study showed that landscape structural metrics including the contiguity index (con), fractal dimension index (frac), related circumscribing circle (cir) and the shape index $(s h p)$ for land use/land cover, soil and geology are significant in explaining hydrological responses in general, and time of concentration, in particular.

Moreover, our findings revealed that regularity and irregularity in the shape of a given patch (e.g., urban and semi-urban, rangeland and agricultural) can affect patch functions (retarding and/or increasing flow accumulation) at the catchment scale, which would, in turn, decrease or increase the times of concentration in the catchments.

It should be noted that the highly permeable geological patches, and the low infilterable soil patches, play a significant and distinct role in advancing or retarding the times of concentration in models for the catchments, depending on the extent of their shape irregularity.

The knowledge obtained regarding landscape metrics in explaining the duration of the time of concentration can help explain the hydrological process explicitly. It would be very useful if future research concentrates on the relationship between the times of concentration of catchments, and landscape composition-representing metrics, and/or landscape configuration-representing metrics.

Acknowledgements. The first author would like to thank the Chinese Academy of Sciences (CAS) and Nanjing Institute of Geography and Limnology (NIGLAS) for supporting this project by providing him with a Visiting Professor fellowship as part of the CAS President's International Fellowship Initiative.

\section{REFERENCES}

Ahearn, D.S., Sheibley, R.W., Dahlgren, R.A., Anderson, M., Johnson, J., Tate, K.W., 2005. Land use and land cover influence on water quality in the last free-flowing river draining the western Sierra Nevada, California. J. Hydrol., 313, 3-4, 234-247. DOI: 10.1016/j.jhydrol.2005.02.038.

Almeida, I.K.D, Almeida, A.K., Aache, J.A.A., Steffen, J.L., Alves Sobrinho, T., 2014. Etimation on time of concentrationof overland flowin watersheds: A review. Geociências, 33, 4, 661-671.

Amiri, B.J., Fohrer, N., Cullmann, J., Hörmann, G., Müller, F., Adamowski, J., 2016. Regionalization of tank model using landscape metrics of catchments. Water Resources Management, 30, 14, 5065-5085.

Amiri, B.J., 2014. Environmental Impacts Assessment. Tehran University Press, University of Tehran, $174 \mathrm{p}$. 
Amiri, B.J., Nanake, K., 2009. Modeling the linkage between river water quality and landscape metrics in the Chugoku district of Japan. Journal of Water Resources Management, 23, 931-956.

Baker, W.L., Cai, Y., 1992. The programs for multiscale analysis of landscape structure using the GRASS geographical information system. Landscape Ecology, 7, 291-302.

Chatterjee, S., Hadi, A.S., Price, B., 2000. The Use of Regression Analysis by Example. John Wiley and Sons, New York, USA.

del Tánago, M.G., Gurnell, A.M., Belletti, B., de Jalón, D.G., 2016. Indicators of river system hydromorphological character and dynamics: understanding current conditions and guiding sustainable river management. Aquatic Sciences, 78, 1, 35-55.

Deelstra, J., Iital, A., Povilaitis, A., Kyllmar, K., Greipsland, I., Blicher-Mathiesen, G., Lagzdins, A., 2014. Reprint of "Hydrological pathways and nitrogen runoff in agricultural dominated catchments in Nordic and Baltic countries". Agriculture, Ecosystems \& Environment, 198, 65-73.

Fang, X., Thompson, D.B., Cleveland, T.G., Pradhan, P., Malla, R., 2008. Time of concentration estimated using watershed parameters determined by automated and manual methods. Journal of Irrigation and Drainage Engineering, 134, 2, 202-211.

Fatehi, I., Amiri, B.J., Alizadeh, A., Adamowski, J., 2015. Modeling the relationship between catchment attributes and in-stream water quality. Water Resources Management, 29, 14, 5055-5072.

Forman, R.T.T., Godron, M., 1986. Landscape Ecology. Wiley, New York.

Gallo, E.L., Brooks, P.D., Lohse, K. A., McLain, J.E., 2013. Land cover controls on summer discharge and runoff solution chemistry of semi-arid urban catchments. Journal of Hydrology, 485, 37-53.

Griffith, J., 2002. Geographic techniques and recent applications of remote sensing to landscape-water quality studies. Water, Air, and Soil Pollution, 138, 181-197.

Grimaldi, S., Petroselli, A., Tauro, F., Porfiri, M., 2012. Time of concentration: a paradox in modern hydrology. Hydrological Sciences Journal, 57, 2, 217-228.

Gustafson, E.J., 1998. Quantifying landscape spatial pattern: what is the state of the art? Ecosystems, 1, 2, 143-156.

He, H.S., DeZonia, B.E., Mladenoff, D.J., 2000. An aggregation index (AI) to quantify spatial patterns of landscapes. Landscape Ecology, 15, 591-601.

Hundecha, Y., Bárdossy, A., 2004. Modeling of the effect of land use changes on the runoff generation of a river basin through parameter regionalization of a watershed model. Journal of Hydrology, 292, 1, $281-295$.

Jaeger, J.A.G., 2000. Landscape division, splitting index, and effective mesh size: new measures of landscape fragmentation. Landscape Ecol., 15, 115-130.

Kearns, F.R., Maggi, K.N., Carter, J.L., Resh, V.H., 2005. A method for the use of landscape metrics in freshwater research and management. Landscape Ecology, 20, 113-125.

Lee, S.W., Hwang, S.J., Lee, S.B., Hwang, H.S., Sung, H.C., 2009. Landscape ecological approach to the relationships of land use patterns in watersheds to water quality characteristics. Landscape and Urban Planning, 92, 2, 80-89.

Li, M.H., Chibber, P., 2008. Overland flow time of concentration on very flat terrains. Trans. Res. Rec., 2060, 133-140.

Lin, Y.P., Hong, N.M., Wu, P.J., Wu, C.F., Verburg, P.H., 2007. Impacts of land use change scenarios on hydrology and land use patterns in the $\mathrm{Wu}-\mathrm{Tu}$ watershed in Northern Taiwan. Landscape and Urban Planning, 80, 1, 111-126.

McGarigal, K., Cushman, S.A., Neel, M.C., Ene, E., 2002. FRAGSTATS: Spatial Pattern Analysis Program for Categorical Maps. Computer software program produced by the authors at the University of Massachusetts, Amherst. Available at the following web site: http://www.umass.edu/ landeco/research/fragstats/fragstats.html.

McGarigal, K., Marks, B.J., 1995. FRAGSTATS: Spatial Analysis Program for Quantifying Landscape Structure. USDA Forest Service General Technical Report PNW-GTR-351.

McCuen, R.H., Wong, S.L., Rawls., W.J., 1984. Estimating urban time of concentration. Journal of Hydraulic Engineering, 110, 7, 887-904.

Neter, J., Kutner, H.M., Nachtsheim, C.J., Wasserman, W., 1996. Applied Linear Statistical Models. Irwin, Chicago, IL, USA.

Niehoff, D., Fritsch, U., Bronstert, A., 2002. Land-use impacts on storm-runoff generation: scenarios of land-use change and simulation of hydrological response in a meso-scale catchment in SW-Germany. Journal of Hydrology, 267, 1, 80-93.

Olang, L.O., Kundu, P.M., Ouma, G., Fürst, J., 2014. Impacts of land cover change scenarios on storm runoff generation: a basis for management of the Nyando Basin, Kenya. Land Degradation \& Development, 25, 3, 267-277.

O’Neill, R.V., Krummel, J.R., Gardner, R.H., Sugihara, G., Jackson, B., DeAngelis, D.L., Milne, B.T., Turner, M.G., Zygmunt, B., Christensen, S.W., Dale, V.H., Graham, R.L., 1988. Indices of landscape pattern. Landscape Ecology, 1, 153-162.

Paul, J.F., Comeleo, R.L., Copeland, J., 2002. Landscape metrics and estuarine sediment contamination in the mid-Atlantic and southern New England regions. Journal of Environmental Quality, 31, 3, 836-845.

Rhode, S., Kienast, F., Bürgi, M., 2004. Assessing the restoration success of river widenings: a landscape approach. Environmental Management, 34, 4, 574-589.

Rutledge, D.T., 2003. Landscape indices as measures of the effects of fragmentation: can pattern reflect process? Department of Conservation, Wellington.

Salimi, E.T., Nohegar, A., Malekian, A., Hoseini, M., Holisaz, A., 2017. Estimating time of concentration in large watersheds. Paddy and Water Environment, 15, 1, 123-132.

Salimi, E.T., Nohegar, A., Malekian, A., Hoseini, M. and Holisaz, A., 2017. Estimating time of concentration in large watersheds. Paddy and Water Environment, 15, 1, 123-132.

Sangani, M.H., Amiri, B.J., Shabani, A.A., Sakieh, Y., Ashrafi, S., 2015. Modeling relationships between catchment attributes and river water quality in southern catchments of the Caspian Sea. Environmental Science and Pollution Research, 22, 7, 4985-5002.

Sun, N., Yearsley, J., Baptiste, M., Cao, Q., Lettenmaier, D.P., Nijssen, B., 2016. A spatially distributed model for assessment of the effects of changing land use and climate on urban stream quality. Hydrological Processes, 30, 25, 4779-4798.

Turner, R.E., Rabalais, N.N., 2003. Linking landscape and water quality in the Mississippi River basin for 200 years. BioScience, 53, 6, 563-572.

Turner, M.G., Gardner, R.H., O'Neill, R.V., 2001. Landscape Ecology in Theory and Practice. Vol. 401. Springer, New York.

Turner, M.G., Gardner, R.H., 1991. Quantitative Methods in Landscape Ecology. Springer-Verlag, New York.

Turner, M.G., 1990. Spatial and temporal analysis of landscape patterns. Landscape Ecology, 4, 21-30.

Uriarte, M., Yackulic, C.B., Lim, Y., Arce-Nazario, J.A., 2011. Influence of land use on water quality in a tropical landscape: a multi-scale analysis. Landscape Ecology, 26, 8, 1151-1164.

Uuemma, E., Roosaare, J., Mander, U., 2007. Landscape metrics as indicators of river water quality at catchment scale. Nordic Hydrology, 38, 2, 125-138.

USDA, 1986. Urban Hydrology for Small Watersheds. Technical Release 55 (TR-55). 2nd Ed. Natural Resources Conservation Service, Conservation Engineering Division.

Soulis, K.X., Dercas, N., Papadaki, C.H., 2015. Effects of forest roads on the hydrological response of a small-scale mountain watershed in Greece. Hydrological Processes, 29, 7, 1772-1782.

Van Nieuwenhuyse, B.H., Antoine, M., Wyseure, G., Govers, G., 2011. Pattern-process relationships in surface hydrology: hydrological connectivity expressed in landscape metrics. Hydrological Processes, 25, 24, 3760-3773.

Wickham, J.D., Riitters, K.H., Wade, T.G., Coulston, J.W., 2007. Temporal change in forest fragmentation at multiple scales. Landscape Ecology, 22, 4, 481-489.

Wijesekara, G.N., Gupta, A., Valeo, C., Hasbani, J.G., Qiao, Y., Delaney, P., Marceau, D.J., 2012. Assessing the impact of future land-use changes on hydrological processes in the Elbow River watershed in southern Alberta, Canada. Journal of Hydrology, 412, 220-232.

Zhou, T., Ren, W., Peng, S., Liang, L., Ren, S., Wu, J., 2014. A riverscape transect approach to studying and restoring river systems: A case study from southern China. Ecological Engineering, 65, 147-158.

Yeo, I.Y., Guldmann, J.M., Gordon, S.I., 2007. A hierarchical optimization approach to watershed land use planning. Water Resources Research, 43, 11, W11416. 